\title{
The Relationship between Saudi English Major University Students' Writing Performance and Their Learning Style and Strategy Use
}

\author{
Miriam A. Alkubaidi ${ }^{1}$ \\ ${ }^{1}$ English Language Institute, King Abdulaziz University, Jeddah, Saudi Arabia \\ Correspondence: Miriam A. Alkubaidi, King Abdulaziz University, English Language Institute, Jeddah, Saudi \\ Arabia. Tel: 96-656-316-1091. E-mail: malkubaidi@kau.edu.sa
}

\author{
Received: January 6, 2014 Accepted: February 9, 2014 Online Published: March 6, 2014 \\ doi:10.5539/elt.v7n4p83 URL: http://dx.doi.org/10.5539/elt.v7n4p83
}

\begin{abstract}
This study investigates the link between writing tasks, learners' learning style preference, and writing strategy use. It also investigates if students with various proficiency levels stem from different learning style preference and use different writing strategies. This research attempts to answer the following research questions: what are the most common learning style preferences of Saudi undergraduate students majoring in English? what are the most common writing strategies used by Saudi students when writing an essay? Is the choice of writing strategy related to a learner's learning style preference and writing task, and how might they be linked with one another? And finally does the use of writing strategies contribute to students' writing performance? The sample of the study consisted of 74 Saudi female undergraduate students in their final year of their bachelor degree in King Abdulaziz University, Saudi Arabia. Two questionnaires were used: (a) the Perceptual Learning Style Preference by Reid (1987), and (b) a writing strategy questionnaire by Petri and Czárl (2003). Moreover, students were asked to choose one of the two TOEFL writing prompts to write an essay. The data received from the returned questionnaires and writing tests were analysed using descriptive and inferential statistics using SPSS19. Results indicated that Saudi female students were mostly auditory and group learners. As for the writing strategies, Saudi learners used more 'before writing' strategies than "during writing" strategies and "reviewing writing" strategies. Results revealed that there was no correlation between the participants' learning style preference and writing strategies, nor their use of writing strategies and their writing proficiency. As a whole, this study contributed to the ESL/EFL field by providing information on Saudi undergraduate female learners in terms of their preferred perceptual learning style, their level of writing proficiency, and indeed their use of writing strategies.
\end{abstract}

Keywords: writing strategies, learning style preference, Saudi learners, writing proficiency, language learning strategies

\section{Introduction}

\subsection{Saudi Arabia and the English Language}

Saudi Arabia is a country where English language is considered a prestigious skill. It has been indicated that 84.9\% of Saudies learn English to get better-paid jobs (Moskovsky \& Alrabai, 2009, p. 6). Even though Arabic is the only official language for Saudies, it is common practice that English is used alongside Arabic in road signs and names of shops, and in interactions between Saudies and non-Saudies. Also, printed materials in places such as banks, airports, travel agencies and post offices are usually in both languages English and Arabic (Al-Haq \& Smadi, 1996, p. 308). In Saudi Arabia, children start learning English in government schools at the age of twelve until they graduate at the age of eighteen. Typically in Saudi Arabia, in particular in government schools, English is learnt through memorization. Students are given paragraphs to memorize without sometimes understanding the whole meanings or indeed the way in which sentences are formed. They pass, achieving high grades by memorizing all of the test questions from the text book. Furthermore, Saudi students, and specifically female students, develop memorization as a sole strategy for learning English - a cognitive factor affecting their second language learning process (Mitchell \& Myles, 2003, p. 24). This has been visibly perceived as an ineffective strategy when it comes to learning English because, as university learners, students need to be creative, develop ideas, and think critically. Without a reasonably solid background in the language, many students find it impossible to come even close to achieving the required outcomes resulting in frustration for both parties; teachers and more importantly the students. 


\subsection{The Research Context}

The educational system in Saudi relies primarily on the teacher as the sole source of knowledge. Many school students are told to memorize their pieces of writing to pass their English language tests. Even though writing is a component of the course that should be taught, not much attention is dedicated to teaching the process of writing in terms of genre, and the required discourse; rather the general focus is usually placed on grammar, spelling, and writing mechanics in general. In the light of the above, McMullen (2009) investigated if Strategy Based Instruction (SBI) would help Saudi EFL students improve their writing abilities. Her research highlights the fact that Saudi students can be taught how to take charge of their own learning using language-learning strategies. Given the scarcity of studies on Saudi students' writing in English, this study attempts to fill the gap by investigating Saudi students' writing performance in relation to their writing strategies and learning preferences. Findings of the study will have immediate implications for different stakeholders in Saudi Arabia, but they will also have implications for other similar EFL contexts too.

At King Abdulaziz University, where the author teaches English as a foreign language, English is taught to all faculties and to both males and females during their freshman year. Males and females are in separate campuses and do not mix at all. In fact, both campuses are on two different locations so they are unable to see, interact, or socialize with one another. In this paper, the focus will be on the female section of the university. The College of Education is part of King Abdulaziz University. The graduates are qualified to be teachers according to their subject matter in which they specialize. Students in the English department are usually divided into groups of 80 to 100 students per group. They study a range of subjects, such as phonetics and phonology, morphology, syntax, drama, poetry, essay writing, novel, teaching English as a second/foreign language (TESOL/TEFL), etc. Most teachers are Saudies and have graduated from Saudi universities. All courses taken by the students are compulsory to complete a Bachelor in English language and literature.

The classrooms are usually quiet, as students usually take upon a passive role in their learning process. Indeed within each group of learners, the environment/atmosphere differs. At times teachers have a group of students with whom they have a great rapport while with others may not. Also, students possess certain beliefs on how learning instruction should be delivered (Lightbown \& Spada, 2003, p. 35). This may well interfere with the learners' attitude towards the language, and consequently may have an influence on the atmosphere of the classroom. As previously mentioned, the typical instruction received at schools differs greatly to the type of instruction delivered in the university. This has been noted by the author with various groups of students. Interestingly, students who are interested in western culture seem most likely to participate in class and it would be safe to say that they have positive attitudes towards the targeted culture. Similarly, they can adopt some identity markers of the targeted social group (Lightbown \& Spada, 2003, p. 33). In light of the description of the context upon the learning process, and the general context, this elucidates the dynamic factors of teachers, learners, and the context upon the learning process as a whole, especially in the Saudi context where the culture plays a prominent role in all paths of life.The objective of this study is to investigate the writing strategies students use when performing writing tasks. We also attempt to link the strategies used with the learners' learning style preference to draw some insights. Specifically, four research questions were formulated to drive the current study; what is the most common language learning style preference (LLSP) found in Saudi undergraduates studying English as their major? What are the most common writing strategies used by Saudi students when writing an essay? Is the choice of writing strategy related to a LLSP and writing task and how might these be linked with one another? And finally, does the use of writing strategies contribute to students' writing performance?

\section{Literature Review}

\subsection{Language Learning Style Preferences (LLSP)}

In a study in 1987, Reid using her own developed LLSP (1984) found that ESL native Arabic speakers' major LLSP were visual, auditory, kinaesthetic, and tactile whereas group and individual learning were minor LLSP. An interesting finding from Reid's data was that ESL students who stayed in the United States for long periods adopted particular learning styles that corresponded with the educational culture to which they had been exposed (Reid, 1998). Later, in 1998, Reid conducted another research on Egyptian EFL learners. The results were parallel to the findings from the earlier research conducted in 1987 indicating that Egyptian students strongly preferred kinaesthetic and tactile learning styles (Reid, 1998).

\subsection{Language Learning Strategies}

In Palestine a study conducted by Khalil (2005) on language learning strategies of 194 high school students and 184 freshman university EFL learners showed that proficiency level and gender were the main factors that had 
an effect on the participants' strategy use. However, in the study, language proficiency level was defined according to the difference of academic levels between university and school learners, meaning the number of years learners were taught English, not according to their performance on language tasks, nor was their proficiency level measured using a standardized test. The procedure the researcher used to choose a sample of participants is not defined and the generalizability of findings is therefore under question. According to Khalil (2005), the university students' results showed that their language proficiency level had an effect on five language learning strategy categories and the results favoured female students over males in 16 individual strategies. In another study conducted on Arabic L1 speakers by Riazi (2007) who investigated the patterns of language learning strategy use of 120 female Arabic-speaking students who were majoring in English at a university in Qatar. The participants were of average proficiency level, and were from all educational levels in the university. Using Oxford's (1990) SILL questionnaire, it was concluded that female Arab students were not different in their use of language learning strategies compared to other cultural groups. Freshman students, in particular, reported more frequent use of language learning strategies than students of other levels. Interestingly, participants reported more use of metacognitive, cognitive and compensation strategies than affective, social and memory strategies. This, in fact, also correlates with Khalil's (2003) findings on Palestinian female learners.

Only one study was conducted on Saudi learners and that is by McMullen (2009). The main purpose of McMullen's research was to improve the writing of Saudi students. The research investigated if gender and academic major had an effect upon the learners' use of LLS. Thus, she attempted to investigate if Strategy Based Instruction (SBI) would indeed help Saudi EFL students improve their writing abilities. She based her SBI program upon Cohen and Weaver's (2006, cited in McMullen, 2009) framework. A total of 165 students participated in the study, 71 males and 97 females. Her research appears to be systematic in her choice of methodology and framework. Her study delivered empirical data suggesting how Saudi EFL students are currently using LLS. It also demonstrates that Saudi students may be taught how to take charge of their own learning using strategies. The results also indicated that females slightly used more LLS than males. However, the questionnaire was not tested for validity and one cannot be sure if the learners exaggerated in their responses as McMullen suggests. She concludes by emphasizing on the great need for research on Saudi students, especially in the area of writing where research is very much needed. This is one of the main reasons this study was conducted, as writing appears to be a common problem among Saudi language learners as well as other ESL/EFL learners.

Both Khalil (2005) and McMullen (2009) agree that gender does have an effect upon the use of LLS though the difference may not be great. McMullen's (2009) research indicates that females use slightly more LLS than males.

2.3 The Intersection between Language Learning Strategies, Language Learning Styles Preferences, and Language Tasks

Based on the Cohen's (2003) framework, the interaction between language tasks, LLSP, and language learning strategies (LLS) are inevitable. Learning strategies do not operate alone but are tied to and interrelated with learning styles and general approaches to learning (Cohen, 1998, p. 15). They are also affected by gender, age and ethnic/cultural differences (Politzer, 1983; Oxford, 1989 cited in Cohen, 1998, p. 15). It is therefore imperative to link strategies and styles to one another. Studies that link LLS to LLSP are quite difficult to find (Cohen, 2003) let alone linking them to tasks. Even though Rossi-Le's (1989) study is fairly back dated, it is only one of the few studies that explore the differences that exist among language learners in terms of their different styles and how might that effect their strategy use. The purpose of the study was to investigate the interplay between an individual's dominant perceptual style and the strategies he/she employs in learning a second language. The sample constituted 147 adult immigrants, 78 males and 69 females, with age ranges between 20 and 52. The participants were enrolled in a community college wherein English was taught as a second language. The major language groups represented in the sample were Chinese, Laotian. Vietnamese, and Hispanic; smaller numbers of students from Eritrea, Haiti, Brazil Cambodia, Morocco, Japan, Poland, Thailand, Korea, and Czechoslovakia. The English proficiency levels of the participants varied from low intermediate to advanced. Their English proficiency was measured by the Michigan Test of Language proficiency. In terms of the instruments used, two self-assessment instruments designed specifically for ESL students, the Perceptual Learning Style Preference Questionnaire and Strategy Inventory for Language Learning (SILL). Overall, results indicated through multiple regression and chi-square analyses that the dominant LLSP for the sample were tactile and kinaesthetic. Secondly, relationships were found between learning styles and strategic approaches to second language learning. The strongest correlation existed between visual learning style and visualization strategies, and for those who preferred tactile and kinaesthetic perceptual learning styles, reported to favour in 
engaging in conversation and seeking out native English speakers meaning that they become actively involved in the learning process. It was also noted that those who enjoyed "group study" were utilizing social as well as interactive strategies. For instance, they enjoyed "working with peers", and "requesting information", and so on. In general, the study demonstrates and highlights the complex system of interactions that exists among various cultural characteristics, LLSP and language learning strategies. Another study of this kind was conducted by Ehrman and Oxford (1990). The study was on a sample of 20 college graduate participants who were a subset of a sample of 79 learners who were studying Turkish at the Foreign Service Institute. The main objective of the study was to describe how students of various psychological types/LLSP preferred specific learning strategies. The instrument used was a language learning strategy system partially based on Oxford's taxonomy. Also, semi-structured interviews provided qualitative data, which was analysed through a coding system. To ensure the reliability of the results, the authors compared their interpretation and comments with one another during the interview. They also conducted a concurrent validity with their own comments and those of the teachers' interviews. Tables were formed to summarise and synthesise various aspects of data for each style preference. They found that there was no significant difference between the sexes in language performance. However, females used more language learning strategies than males, but females and males who shared the same psychological types shared the same learning strategies. This study is ground-breaking in terms of its positive potentiality for learning strategy training according to learners' style preferences. Nevertheless, this study does have its limitations which both authors mention. That is, some learners may have used unconscious strategies that cannot be identified. This can cause some ambiguity as we are unable to pinpoint those strategies. The study was carefully structured and it seems that all measures were taken to ensure the reliability and validity of the study. In a comparative investigation study conducted by Wong and Nunan (2011) into the learning styles and strategies of effective and ineffective language learners on one hundred and ten undergraduate university students in Hong Kong, found that the dominant style for more effective students was "communicative" while for less effective students it was "authority-oriented. The participants were categorized as 'more effective' or 'less effective learners', on the basis of their scores on a standardized public English examination administered at the end of secondary school. The instrument used was an online questionnaire to collect learning strategy preferences as well as patterns of language practice and use. The results indicated clear differences in strategy preferences, overall style, or learning orientation, out of class language use and attitudes towards English. The most common style for more effective students was "communicative" while for less effective students it was "authority-oriented". Most of studies in the fields of LLS and LLSP seem to give more an overview of definitions and classifications with debatable discussions about the definition of the constructs. As reviewed, there are very few studies that deal with all three variables, LLS, LLSP along with language tasks. Evidently though, there are numerous studies that deal with the mentioned constructs along with other variables, such as gender and proficiency.

\section{Theoretical Framework}

This research is based on a framework suggested by Cohen (2003) illustrating the connection between tasks, LLSP and the strategies they use in dealing with tasks. A task encompasses various characteristics. It can range from authentic to inauthentic, from motivating to non-motivating (Cohen, 2003) (see Figure1). The task does not necessarily hold one characteristic but may hold a combination of features. Based on the task and the individual learner's LLSP, the learner will decide on a configuration of strategies in response to the assigned task. The choice of strategies is likely to depend upon the LLSP and the task at hand. Many factors indeed contribute to the choice of strategies, such as level of language proficiency, age, and experience in learning the language, motivation as well as contextual factors and many more. However, one may draw upon some general inferences on how an individual learner of a particular learning style chooses their strategies depending upon the features of the task. 


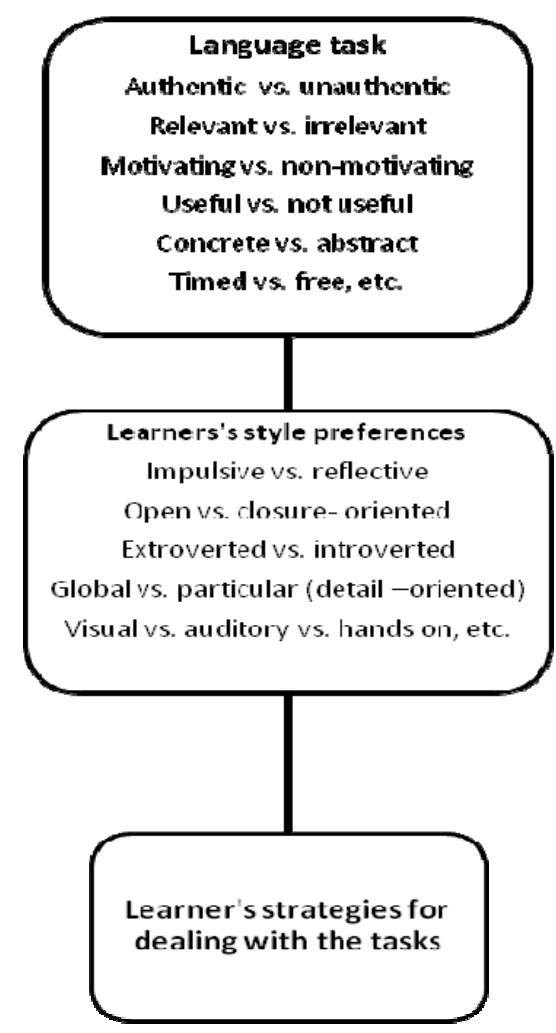

Figure 1. Cohen's (2003) framework for the relationship among task, learner's style preference, and strategies

\section{Methods}

This section describes in detail how the study was conducted, including conceptual and operational definitions of the variables used in the study. Different types of studies will rely on different methodologies; however, a complete description of the methods used enables the reader to evaluate the appropriateness of methods and the reliability and the validity of the result. It also permits experienced investigators to replicate the study.

\subsection{Participants}

The sample of the study includes 74 Saudi university students who were in the final year of their Bachelor's degree. The male and female campuses are segregated in Saudi Arabia, and thus the author could access only female students. They were all aged between 21 and 25 years with Arabic as their first language. The procedure used to choose the sample was a convenience sampling approach as the participants were students whom we were able to access (McKay, 2006, p. 37). The data collection was performed in their educational setting.

\subsection{Instruments}

To collect required data, two questionnaires and a writing task were used. As Dörnyei (2003) points out, survey questionnaires are useful in saving time and effort during the research. While surveys are used extensively in applied linguistic research, they are not without their problems. One of the major problems with survey questionnaires is the reliability and validity of participants' responses. Details of the two questionnaires and the writing task are presented below.

\subsubsection{Writing Strategy Questionnaire}

Petri and Czárl (2003) questionnaire was used to capture the writing strategies used by the participants of this study. This instrument is based on Flower and Hayes' cognitive model of first language processing with the addition of some items related specifically to second language learners. The instrument was devised to survey the "self-reported writing strategies of a large number of non-native speakers of English who write in English for academic purposes" (Petri \& Czárl, 2003, p. 188). This suited the context of this study as all participants were non-native speakers and they were English major students who had to write in English for academic purposes for 
courses such as phonetics and phonology, poetry, and drama. Similarly, this questionnaire was particularly relevant as it attempts to find out what strategies are useful and manageable for assignments for content courses (Petri \& Czárl, 2003).

In terms of the reliability of the questionnaire, Petri and Czárl (2003) checked its internal consistency using the Cronbach alpha coefficient. The coefficient obtained was 0.634. In this study it was found that the Cronbach alpha coefficient was .833 , which is a high index of reliability. The questionnaire was also checked for its validity by Petri and Czárl. Three types of validity were checked, content, construct and response validity, in order to check its wording, interpretation and the general overall flow of the questionnaire from how the learners felt about individual items down to their clarification of responses in accordance to the scale given. Correlations were drawn from both the quantitative and qualitative data. The validity of the responses did not show any validity problems. The questionnaire was translated into Arabic to prevent any language barrier and thus increasing the reliability of the responses. The translated version of the questionnaire was back-translated by another linguist researcher for accuracy of the translation. Minor language changes were made to the Arabic translation of the questionnaire as a result of the comparison of the original and the translated version. These changes were made in two Arabic sentences. The reliability of the questionnaire in this study using data from the Arabic version was computed through Cronbach's Alpha and was found to be 0.833 .

\subsubsection{Perceptual Learners' Style Preferences Questionnaire}

The second questionnaire used in the current study was the perceptual LLSP questionnaire which is a self-reporting questionnaire developed on the basis of previous learning style instruments (Reid, 1987). It is constructed specifically for non-native speakers (NNSs). It measures six LLSP: visual, auditory, kinaesthetic, tactile, and group and individual learning. The last two are aspects of learning. Reid (1990) aimed to create a validated instrument that was simple so that it would be comprehendible to EFL learners. In total, 30 statements were formed with a 5-point Likert scale. This instrument was suitable for both the purpose and the scope of the present study. In an interesting article by Reid (1990) the methodological steps taken to achieve the reliability and validity of the survey are described. Initially, the questionnaire was piloted as it was important to norm it. In the pilot testing, Reid doubled the number of statements for each individual construct to test if the elicited responses matched. The pair correlation would signify that learners fully comprehended the items. She then consulted with second language experts to ensure that the statements were crystal clear. In order to ascertain the reliability of the survey, the split-half method was conducted. The reliability of the questionnaire for this study was computed and the Cronbach's Alpha resulted in .447, which is a low index. Ried (1990, cited in Petri \& Czárl, 2003) mentions that .60 is an acceptable correlation level for a self-reporting questionnaire of perceptual learning styles.

Therefore, since the index for this research is below .60, the reliability of the questionnaire may be under question. It was necessary that a survey was designed particularly for EFL learners be chosen to be administered as it would fit the targeted population of the present study. Also, the fact that the questionnaire was not tedious was an added advantage as participants had a lot to do including writing an essay.

\subsubsection{Writing Task}

In order to have an objective index of the participants' writing performance they were assigned two writing prompts to choose one and to write an essay on it. Given the participants' backgrounds and level of English language proficiency, the prompts were selected to have personal implications for the participants so that participants would know something about the topics as Jacobs et al. (1981) advises. This helps to motivate the learners to write the best of their ability. Also, the choice of two prompts allowed the participants to choose a topic most suited to them so that they could produce a good piece of writing. In addition to the above criterion, the topics chosen were culturally pertinent to Saudi participants. This demonstrates the validity of the writing performance test (Oller, 1979). Of the 74 participants 37 chose the first prompt and 37 chose the second prompt. The first prompt asked the students if they agreed or disagreed if parents are the best teachers, whereas the second prompt asked the students if they thought that some people can learn better by themselves than with a teacher. In both prompts, students were requested to provide specific reasons and examples to develop their essay. In terms of validity, the participants had twice the amount of time usually allowed for the TOEFL test. This was to provide participants with enough time to write drafts, rewrite, and use various writing strategies to complete their writing as 30 minutes would be only enough to write a first draft (Alderson, 2009). The researcher took a few precautions to avoid any inconsistency in the reliability of the scoring. Firstly, all writing samples were typed so that the handwriting did not influence the evaluator. Jacobs et al. (1981) rating scale which is an analytic scale for scoring writing was used to score participants' writings. This scale was chosen because the 
scoring criteria encompass everything Saudi undergraduate students are taught during the semester. Jacobs and his associates' (1981) profile for writing compositions were adopted also because of its rationale behind its design. Jacobs et al. (1981, p. 35) suggest that "the definition of communicative effectiveness may vary from reader to reader." Therefore, the scale describes specific standards that every reader/evaluator must apply to come up with the same or very similar scores as these forces readers to look into various aspects of the writing. These standards assist in assuring the validity and reliability of scoring.

To endure consistency of the ratings, ten essays were randomly chosen to be scored by two raters. In order to make sure the rating was consistent, three copies of the ten essays were made. The first copy was rated by the researcher who then left it for a week. The following week, the second copy was rated. Results of the two ratings were compared for intra-rater reliability. The third copy was given to another rater. The criteria of scoring, the adapted version of Jacobs et al. (1981) profile for writing compositions, was explained to the second rater. She then rated the ten samples of writing. The reliability result of the researcher's evaluation resulted in 0.76 , which was not high enough to depend upon. Therefore, a second attempt was applied to achieve a higher value. In the second attempt, the result was 1.0, which is an index that is highly reliable. In addition, another rater who was an English teacher in the English Department in the college of Education rated the same papers, in which the researcher evaluated. The other rater's evaluation resulted in an index value of 0.53 . Further discussion took place between the rater and researcher, so that there would be consistency in the writings' evaluations. When the second set of evaluation was made, a higher index of 0.85 was achieved. Once the intra- and inter-rater reliability indices reached the desired level, all the essays were scored by the first rater.

\subsection{Data Collection Procedures}

The researcher explained to the participants what was asked of them starting with the Perceptual Learning Style Questionnaire (Reid, 1987) all instructions were given in Arabic. The researcher stressed to students that they should write a nickname that they would remember so that the researcher could match all documents of the data with the same nickname. It was also stressed to the participants that they could ask the researcher for clarification if they were not sure of their understanding of any of the items. Some participants asked about several items which appeared to be a positive indication that they found the study interesting and thus motivating to participate in. In turn, this supports the validity of the data collected. After the participants completed the LLSP questionnaire, they were given the essay writing test which was a choice between two TOEFL writing prompts. The researcher pointed out to the participants that they were allowed to use dictionaries if they needed to. However, not many used a dictionary. The few students who did use dictionaries, used electronic ones for translating from Arabic to English. Because the researcher knew that writing is a challenging task for students, it was decided to allow the participants to complete the task in one hour. In fact, some participants needed extra time and so the researcher allowed them to have that extra time. After participants completed their writing, the writing strategies questionnaire was distributed. All data collection was completed in one session as described.

\section{Data Analysis}

Both descriptive and inferential statistics were used to analyse the data. This study had two independent variables, namely, writing strategies and LLSP with the dependent variable being the writing proficiency. Descriptive statistics for the writing strategies, LLSP questionnaire and writing proficiency are calculated and presented. In addition, to identify if there is a correlation between the participants writing proficiency and their reported use of writing strategy, a correlation matrix is computed. In order to further investigate if the use of writing strategies was different for different levels of writing proficiency, an independent t-test was calculated. Lastly, a one-way ANOVA within subjects is computed to identify if proficiency affected the use of the three writing strategies sets.

\section{Results}

\subsection{Students' Writing Performance}

Measures of central tendency and dispersion were computed for the writing proficiency variable and arepresented in Table 1. 
Table 1. Measures of central tendency and dispersion

\begin{tabular}{lcc}
\hline & Valid & 74 \\
& Missing & 0 \\
\hline Mean & & 29.95 \\
Median & 29.00 \\
Mode & $26^{\mathrm{a}}$ \\
Std. Deviation & 7.290 \\
Minimum & 14 \\
Maximum & & 45 \\
\hline
\end{tabular}

a. Multiple modes exist. The smallest value is shown

\subsection{Writing Strategy Use}

Descriptive statistics for the writing strategies questionnaire was computed and results are presented in Table 2 .

Table 2. Descriptive statistics for the writing strategies questionnaire

\begin{tabular}{lccc}
\hline & $\mathrm{N}$ & Mean & Std. Deviation \\
\hline WS before W & 73 & 24.0548 & 3.58581 \\
WSWW & 65 & 47.8615 & 8.19656 \\
WS RV & 58 & 44.2241 & 7.33423 \\
WS Overall & 53 & 38.9057 & 5.26006 \\
Valid N (listwise) & 53 & &
\end{tabular}

As presented in Table 2, the mean for drafting strategies 'while writing' is the highest (47.86) while the mean for 'before writing' strategies are the lowest (24.05).

\subsection{Learning Style Preferences}

Table 3 presents descriptive statistics for LLSP. Results indicate that Saudi students could be ordered in terms of their LLSP as group learners (23.94), visual (21.72), individual learners (21.5), auditory (21.23), kinaesthetic (19.45), and tactile (19.1).

Table 3. Descriptive statistics of the LLSP questionnaire

\begin{tabular}{llcc}
\hline & $\mathrm{N}$ & Mean & Std. Deviation \\
\hline Indiviual LS & 61 & 21.5082 & 5.91783 \\
Kinestetic LS & 59 & 19.4576 & 7.56426 \\
Group LS & 63 & 23.9365 & 8.42399 \\
Auditory LS & 68 & 21.2353 & 5.42002 \\
Tactile LS & 56 & 19.1071 & 5.94422 \\
Visual LS & 59 & 21.7288 & 4.46376 \\
Valid N (listwise) & 42 & & \\
\hline
\end{tabular}

\subsection{Writing Performance and LLSP}

A one-way ANOVA within subjects was conducted to find out if there was any significant difference in LLPScategories in terms of writing performance. Results presented in Table 4 showed no significant difference among LLPS categories in relation to writing performance 
Table 4. One way ANOVA within subjects on the LLSP and their writing performance

\begin{tabular}{lcccccc}
\hline & & Sum of Squares & df & Mean Square & F & Sig. \\
\hline \multirow{3}{*}{ Indiviual LS } & Between Groups & 40.770 & 1 & 40.770 & 1.089 & .301 \\
& Within Groups & 1983.667 & 53 & 37.428 & & \\
& Total & 2024.436 & 54 & & & \\
\hline \multirow{3}{*}{ Kinestetic LS } & Between Groups & 138.297 & 1 & 138.297 & 2.615 & .112 \\
& Within Groups & 2802.503 & 53 & 52.877 & & \\
& Total & 2940.800 & 54 & & & \\
Group LS & Between Groups & 4.504 & 1 & 4.504 & .059 & .809 \\
& Within Groups & 4211.496 & 55 & 76.573 & & \\
& Total & 4216.000 & 56 & & & \\
\hline \multirow{3}{*}{ Auditory LS } & Between Groups & 24.287 & 1 & 24.287 & .824 & .368 \\
& Within Groups & 1797.935 & 61 & 29.474 & & \\
\hline \multirow{3}{*}{ Tactile LS } & Total & 1822.222 & 62 & & & \\
& Between Groups & 10.008 & 1 & 10.008 & .305 & .583 \\
& Within Groups & 1608.345 & 49 & 32.823 & & \\
\hline \multirow{2}{*}{ Visual LS } & Total & 1618.353 & 50 & & & \\
\hline & Between Groups & 42.542 & 1 & 42.542 & 2.076 & .156 \\
& Within Groups & 1086.185 & 53 & 20.494 & & \\
\hline
\end{tabular}

\section{Discussion}

\subsection{The Writing Strategies Used by Saudi Students}

Saudi university students were found to use 'drafting strategies' while writing the most. This would include strategies such as rereading what they write, using bilingual/monolingual dictionaries, checking grammar and vocabulary, and checking the plan and changing it. On the other hand 'before writing' strategies was scored the lowest. Therefore, strategies such as reviewing the requirements, writing notes about the topic, outlining, looking at samples of wiring and thinking of what to write are strategies used the least. This can evidently affect the quality of the final piece of writing produced by students. The result can also imply that 'before writing' strategies may not be used in their native language.

\subsection{The Most Common LLSP Found in Saudi Students}

Results indicated that group learning was most preferred by the participants of the study, then visual, individual, auditory, kinaesthetic and lastly tactile learning. These results have some similarities to Reid's (1987) study who found that the major learning styles of native Arabic speakers were visual, auditory, kinaesthetic and tactile, while group and individual learning were minor learning styles. This study corresponds with the idea that Arab learners prefer to be actively involved in the learning process. This is the reverse to what actually happens in language classrooms in Saudi Arabia where the students usually take on a passive role in the learning process, listening anxiously to what the teacher instructs them to do. Results demonstrate that Saudi students may want to take hold of their own learning and be active in the process of learning. The result of this part of the study provides confirmation of some of the common LLSP previously found among Arabic speaking students. This does not; however suggest that all Arabic speaking students possess the sameLLSP, but rather an indication to the way most of these students learn the English language

\subsection{The Writing Performance of Saudi University Students}

The writing performance of Saudi university students was generally poor. Given the results obtained, both high and low writing performance groups were almost equal. When evaluating the writing, we generally noticed that students were weak within not only the writing structure, but also in ideas and vocabulary. Some only wrote a few lines, others repeated the same ideas and vocabulary items. Some even inserted some Arabic words. The low 
writing performance could be due to their low language proficiency in general. The English department does not strengthen the language itself, but rather focuses on literature subjects, such as poetry, drama, along with linguistic courses, such as morphology, syntax, and phonetics. Most students pass even though they are unable to compose a paragraph, because they memorize. Saudi schooling is largely based on memorization rather than on critical thinking. Therefore, writing poses a massive challenge to students wherein they have to think for themselves rather been told what to think.

\subsection{The Choice of Writing Strategies Related to LLSP}

The results of the study demonstrated that there was no correlation between the writing strategies used by Saudi students and their LLSP. In fact, in many cases it appeared that there was a negative correlation; for instance, auditory, kinaesthetic, tactile, visual and group learning when correlated with writing strategies implied that the more strategies a learner uses, the less audio or tactile the learner becomes. This result seems odd because the negative correlation occurred in five learning styles out of six. These results conflict withother findings (Rossi-Le, 1989; Ehrman \& Oxford, 1990). The low correlation of writing strategies to the LLSP can be attributed to several factors. First, there are many variables besides writing strategies, for example linguistic knowledge, background knowledge, motivation, and acculturation, which account for second language acquisition (Ellis, 2008; Park, 2010). Therefore, there will be a limitation for one variable, for instance writing strategies, to account for LLSP. Secondly, and more importantly, the researcher wonders if the students actually answered the questions about their behaviours and preferences according to what they actually do when writing.The application of writing strategies is not stressed in the Saudi educational system; rather the theory of how to write is presented. This is merely a speculation and one cannot tell for certain if this was one of the reasons behind the data results. Also, the reason behind the conflicting findings could be due to the inadequate knowledge of unsuccessful learners of the strategies they actually use in comparison to what they report doing (Vann \& Abraham, 1990). In fact, in Vann and Abraham's (1990) study, unsuccessful female Saudi learners demonstrated that they were active strategy users, but their application of those strategies was inappropriate. This could also explain the current results. It could happen to be that learners were active strategy users, but used them inappropriately. Consequently their interpretation and the way they reported their use in the questionnaire could be under question. Thirdly, the low correlation might be due to learners' automaticity of writing strategies and failure to report the strategies they used subconsciously. They may also have exaggerated their answers in the questionnaire.

\subsection{The Use of Writing Strategies in Relation to Students' Writing Performance}

An independent sample t-test was conducted to compare high and low proficiency learners' use of writing strategies. The results indicated that there was no significant difference in the use of writing strategies between the two groups. To further investigate if indeed proficiency had no effect upon the use of strategies, a one-way ANOVA analysis was conducted on both groups and each writing strategy subsets, including writing strategies 'before writing', writing strategies "when writing", and writing strategies "when revising". However, again results showed that the use of strategies had no significant effect on proficiency. Khalil (2005) found that proficiency has no effect on language learning strategies; however, his definition of proficiency differed to the one in this study. Abdullah's (2009) research confirmed that there were similarities between good and weak learners; however their patterns of writing strategy use differed. It seems logical to assume that more proficient learners would use more writing strategies than less proficient learners; however, the results here contradict this notion. This could be because good and weak students do not differ in their use of writing strategies. The difference may lie in the way they use strategies and in their comprehension of what writing strategies are, and if indeed they apply them when writing.Also, studies have shown that strategies among writers may differ more than between L1 and L2 writing strategies of the same writer (Krapels, 1990, cited in Petri \& Czárl, 2003). This means that writers transfer their writing skills in Arabic, and this would result in a lack of L2 writing competence caused by weak writing skills in L1. The researcher was informed by one of a lecturer in the College of Education who teaches the participants of this study, and informed her that she had asked the students to write an essay in Arabic in any topic they wished. This lecturer's purpose of this experiment was to check the quality of writing in L1 and to compare itwith their L2 writing. She said that they were as weak in L1 as they were in L2 mainly because students lacked ideas and creativity. Even though this was an informal conversation between the researcher and lecturer, it can nevertheless shed some possible reason behind the results obtained in this study.The results could also be due to exaggeration in the participants' responses in the questionnaires, or they may have not paid much attention to each individual item when answering. Since the participants were given two questionnaires in addition to writing an essay, they may have been tired, and therefore lacked concentration in answering the last questionnaire, which was the one about writing strategies used. Also, as mentioned previously, 
the students most probably were unaware of the writing strategies they used, or they may have thought that they were applying a particular writing strategy when, in fact, they were not. Similarly, Vann \& Abraham (1990) found that the repertoire of strategies of successful and unsuccessful learners matched. It is essential to mention here that writing strategies, and second language writing in general, is not given much attention in Saudi Arabia, and this could be a reason that the data presents itself as it does.

\section{Limitation of the Study}

The researcher admits that although results of this study may be perceptive, it is imponderable to fully cover the areas outlined. The scope of the research is limited in terms of its number and type of participants, and the type of data collected being quantitative only. This was due to time constraints. Even so, this study can perhaps assist us in gaining some tangible thought-provoking aspects of Saudi learners while performing writing tasks, which may pave the way for future research.

\section{Summary}

Due to the poor writing skills of Saudi university students, this study was conducted to investigate if writing strategies were linked with LLSP when performing a writing task. Proficiency was an added variable to distinguish the differences, if any, between high and low proficient learners in their use of writing strategies. For Saudi students, writing in English is found to be a very challenging task. There has been only one single study in dealing with language learning strategies in a Saudi context. From that perspective, there seemed to be a gap in the literature. As a result, the study at hand attempted to fill in that gap. The study is based on a framework suggested by Cohen (2003) illustrating the connection between the three mentioned variables. The researcher expected a type of correlation between the three variables as suggested by the theoretical framework developed by Cohen (2003). The results were contradictory to many other studies found in the literature. No correlations were found, and there was no distinction between high and low proficient learners in terms of writing strategy use. The participants of the study were in their final year of their Bachelor's degree in English Language and Literature. All seventy-four participants were female aged between 21-25 years, and Arabic was their first language. They were from the College of Education, King Abdulaziz University. Questionnaires were used to gather information from the participants. The dependant variable in the study was the writing performance of the students. Petri and Czárl's (2003) questionnaire was administered to identify the writing strategies used by the participants. The second questionnaire administered in the study was the perceptual LLSP, which is a self-reporting questionnaire developed on the basis of previous learning style instruments (Reid, 1987). It is specifically constructed for NNS. It measures six LLSP: visual, auditory, kinaesthetic, tactile, and group and individual learning. In order to have an objective index of the participants' writing performance they were assigned two writing prompts, adopted from TOEFL prompts, to choose from in order to write an essay. In addition, prompts were nominated from the tests and they were selected according to their familiarity to participants. In other words, they would know something about the topics as Jacobs et al. (1981) advises. This can also add to the validity of the writing performance test (Oller, 1979). After the participants completed the LLPS questionnaire, they were given the essay writing test. The researcher pointed out to the participants that they were allowed to use dictionaries if they needed to, and also welcomed any questions or queries they might have. Extra time was permitted for participants who needed it as the researcher knew that writing is a challenging task. An adapted version of Jacobs et al. (1981) scoring scale was used to rate the participants' essays. This scale was basically chosen because the criteria of scoring included everything Saudi undergraduate students are taught during their time of study. In terms of data analysis, primarily descriptive statistics were calculated to measure writing strategies use, their writing performance and LLSP. This study had two independent variables of writing strategy use, language LLSP. For the analysis of the data, descriptive statistics was used along with a correlation matrix to investigate the correlation if any between the students' writing performance and their reported use of writing strategies. Also, an independent t-test was computed to compare the use of writing strategies among the two writing proficiency levels. Finally, a one-way ANOVA within subjects was run to see if there is any significant difference among the LLPS categories in terms of students' writing performance. As indicated no significant correlations were found among any of the variables overall and in terms of their categories indicating the uniqueness of the sample of the study.The present study found that the most common language learning style found in Saudi female undergraduatestudents were group learners, visual, individual learners, auditory, kinaesthetic, and tactile learning styles. Saudi university students were found to use more 'while writing' strategies the most, while 'pre-writingstrategie' were the least used when attempting to write an essay.There is no correlation between the writing strategies and the participants' LLSP.Therefore, the choices of writing strategies were not linked to any of the various LLSP, such as auditory, visual, tactile, kinaesthetic, group, and individual learning styles. Furthermore, there is no significant correlation found between 
the use of strategies and the writing performance of the participants. The high and the low writing proficiency of Saudi learners displayed no difference in their use of writing strategies. Participants' writing proficiency was not an indicator of the learners' choice of writing strategies. Results demonstrated that there was no difference between the high and low proficient learners in their choice of writing strategies. Therefore, Cohen's (2003) theory that links LLS with LLSP along with tasks does not seem to apply to the current study.

\section{Recommendations for Future Studies}

Even though precautions were taken in preparing this study in terms of choosing the methodology, the process of data collection, and ensuring the validity and reliability of the questionnaires, it nevertheless is not immune to criticism. The findings cannot be generalised because of the limited number and type of participants (being only female), because of the setting (being only one educational institution), and because the data collection methods are purely quantitative which does not allow for much insight, elaboration or explanation to why the results are so. There is no qualitative data to back up the quantitative one. Thus, more studies should be conducted among different learners in different contexts using various data collection methods to replicate the findings of this study and to also shed light on the use of writing strategies and how this relates, if at all, to language learningstyle preferences. For future studies, it is suggested that think-aloud protocols as well as interviews with students can be used to enable us to expand our knowledge of students' use of writing strategies when attempting writing tasks. Furthermore, due to the time limitation, the researcher was unable to account for different variables such as learning aptitude, motivation, anxiety, etc. Therefore, it is suggested that future studies should investigate these different variables so that individual differences in second language learning can be better understood.

\section{Acknowledgments}

The author would like to thank Dr. Mehdi Riazi for his valuable comments and guidance in relation to editing this article. Also, a special thank you to Ms. Sawsan Al-Jahadali and Dr. Nora Al-Malki for their valuable input and assistance during the data collection. (Note: portions of the above article appeared in Miriam Alkubaidi's unpublished MA dissertation).

\section{References}

Abdullah, M. (2009). The Writing Strategies used by Engineering ESL Malay Learners.

Al-Haq, F., \& Smadi, O. (1996). Spread of English and westernization in Saudi Arabia. World Englishes, 15(3), 307-317.

Alderson, J. C. (2009). Test review: Test of English as a Foreign Language ${ }^{\mathrm{TM}}$ : Internet-based Test (TOEFL iBT $\left.{ }^{\circledR}\right)$. Language Testing, 26(4), 621.

Cohen, A. D. (1998). Strategies in learning and using a second language. London: Longman.

Cohen, A. D. (2003). The learner's side of foreign language learning: Where do styles, strategies, and tasks meet? IRAL, 41(4), 279-292.

Dörnyei, Z. (2003). Questionnaires in second language research: Construction, administration, and processing. Lawrence Erlbaum.

Ehrman, M., \& Oxford, R. (1990). Adult language learning styles and strategies in an intensive training setting. The Modern Language Journal, 74(3), 311-327.

Ellis, R. (2008). The study of second language acquisition (2nd ed.). Oxford University Press.

Jacobs, H. L., Zinkgraf, S. A., Wormuth, D. R., Hartfiel, V. F., \& Hughey, J. B. (1981). Testing ESL composition: A practical approach. Newbury House Rowley, MA.

Khalil, A. (2005). Assessment of language learning strategies used by Palestinian EFL learners. Foreign Language Annals, 38(1), 108-117.

Lightbown, P. M., \& Spada, N. (2003). Factors affecting second language learning. In C. N. Candlin, \& N. Mercer (Eds.), English language teaching in its social context: A reader (pp. 28-43). London: Routledge.

McKay, S. (2006). Researching second language classrooms. Routledge.

McMullen, M. G. (2009). Using language learning strategies to improve the writing skills of Saudi EFL students: Will it really work? System, 37(3), 418-433.

Mitchell, R., \& Myles, F. (2003). Second language learning: Key concepts and issues. In C. N. Candlin, \& N. Mercer (Eds.), English language teaching in its social context: A reader (pp. 11-27). London: Routledge. 
Moskovsky, C., \& Alrabai, F. (2009). Intrinsic Motivation in Saudi Learners of English as a Foreign Language. The Open Applied Linguistics Journal, 2(1), 1-10.

Oller, J. W. (1979). Language tests at school. Longman.

Oxford, R., \& Crookall, D. (1989). Research on language learning strategies: Methods, findings, and instructional issues. Modern Language Journal, 73(4), 404-419.

Oxford, R. L. (1990). Language learning strategies: What every teacher should know. Newbury House.

Oxford, R. L. (2008). Research on second language learning strategies. Annual Review of Applied Linguistics, 13, 174-187.

Park, G. P. (2010). Investigation into Learning Strategies Used by Effective and Less Effective EFL Learners in Korea. Asian Social Science, 6(8), 3.

Petri, B., \& Czárl, B. (2003). Validating a writing strategy questionnaire. System, 31(2), 187-215.

Reid, J. M. (1987). The learning style preferences of ESL students. TESOL Quarterly, 21(1), 87-111.

Reid, J. M. (1990). The dirty laundry of ESL survey research. TESOL Quarterly, 323-338.

Reid, J. M. (1998). Teachers as perceptual learning styles researchers. In J. M. Reid (Ed.), Understanding learning styles in the second language classroom. Prentice Hall Regents.

Riazi, A. (2007). Language Learning Strategy Use: Perceptions of Female Arab English Majors. Foreign Language Annals, 40(3), 433-440.

Rossi-Le, L. (1989). Perceptual learning style preferences and their relationship to language learning strategies in adult students of English as a second language.

Vann, R. J., \& Abraham, R. G. (1990). Strategies of unsuccessful language learners. Tesol Quarterly, 24(2), 177-198.

Wong, L. L., \& Nunan, D. (2011). The learning styles and strategies of effective language learners. System, 39(2), 144-163.

\section{Copyrights}

Copyright for this article is retained by the author(s), with first publication rights granted to the journal.

This is an open-access article distributed under the terms and conditions of the Creative Commons Attribution license (http://creativecommons.org/licenses/by/3.0/). 